\title{
What is an evidence map? A systematic review of published evidence maps and their definitions, methods, and products
}

Isomi M. Miake-Lye ${ }^{1,2^{*}}$, Susanne Hempel ${ }^{3}$, Roberta Shanman ${ }^{3}$ and Paul G. Shekelle $e^{1,3,4}$

\begin{abstract}
Background: The need for systematic methods for reviewing evidence is continuously increasing. Evidence mapping is one emerging method. There are no authoritative recommendations for what constitutes an evidence map or what methods should be used, and anecdotal evidence suggests heterogeneity in both. Our objectives are to identify published evidence maps and to compare and contrast the presented definitions of evidence mapping, the domains used to classify data in evidence maps, and the form the evidence map takes.
\end{abstract}

Methods: We conducted a systematic review of publications that presented results with a process termed "evidence mapping" or included a figure called an "evidence map." We identified publications from searches of ten databases through $8 / 21 / 2015$, reference mining, and consulting topic experts. We abstracted the research question, the unit of analysis, the search methods and search period covered, and the country of origin. Data were narratively synthesized.

Results: Thirty-nine publications met inclusion criteria. Published evidence maps varied in their definition and the form of the evidence map. Of the 31 definitions provided, $67 \%$ described the purpose as identification of gaps and $58 \%$ referenced a stakeholder engagement process or user-friendly product. All evidence maps explicitly used a systematic approach to evidence synthesis. Twenty-six publications referred to a figure or table explicitly called an "evidence map," eight referred to an online database as the evidence map, and five stated they used a mapping methodology but did not present a visual depiction of the evidence.

Conclusions: The principal conclusion of our evaluation of studies that call themselves "evidence maps" is that the implied definition of what constitutes an evidence map is a systematic search of a broad field to identify gaps in knowledge and/or future research needs that presents results in a user-friendly format, often a visual figure or graph, or a searchable database. Foundational work is needed to better standardize the methods and products of an evidence map so that researchers and policymakers will know what to expect of this new type of evidence review.

Systematic review registration: Although an a priori protocol was developed, no registration was completed; this review did not fit the PROSPERO format.

Keywords: Evidence map, Evidence synthesis, Systematic review

\footnotetext{
* Correspondence: isomi.miake-lye@va.gov

${ }^{1}$ Evidence-based Synthesis Program (ESP) Center, Veterans Affairs Greater LoS

Angeles Healthcare System, 11301 Wilshire Blvd, Los Angeles, CA 90073, USA

2Department of Health Policy and Management, Fielding School of Public

Health, University of California, Los Angeles, 640 Charles E Young Dr S, Los

Angeles, CA, USA

Full list of author information is available at the end of the article
} 


\section{Background}

There is growing variation in evidence synthesis methodology to meet the different objectives evidence synthesis can support. The classic systematic review and meta-analysis are both rigorous and produce detailed information about narrow questions, but they are resource intense and the work burden limits the scope of what can be covered [1]. To meet a variety of user needs, offshoots of the classic model have been developed within the evidence synthesis realm; for example, rapid reviews cater to more urgent deadlines but may not adhere to all the methods of a systematic review [2], scoping reviews accommodate larger bodies of literature for which detailed synthesis is not needed [3], and realist reviews specialize in exploring how complex interventions work and frequently include evidence excluded from classic systematic reviews [4].

These new variants on the classical systematic review are at various phases in development. Determining the unique contributions and methods of each of these new synthesis method offshoots is a challenge. Systematic reviews and meta-analyses have a standardized process for conduct and reporting, codified in the Institute of Medicine standards and Preferred Reporting Items for Systematic Reviews and Meta-Analyses (PRISMA) reporting guidelines [5, 6]. The Realist And Meta-narrative Evidence Syntheses: Evolving Standards (RAMESES) publication standards for realist syntheses and meta-narrative reviews were published in $2013[7,8]$, and scoping review reporting guidance is underway as of 2014 using the Enhancing the QUALity and Transparency Of health Research (EQUATOR) Network [3]. Rapid reviews, also sometimes referred to as evidence summaries [9], have received increased interest, with a journal series and dedicated summit in 2015 [10, 11], as well as multiple articles on rapid review methodology $[9,12,13]$, but no official standards have been released.

Evidence mapping is the newest of these new evidence review products. In 2002, there were no published evidence maps, and as recently as 2010, only ten such publications could be identified. In addition, evidence mapping has yet to undergo the scrutiny and development of these other methodologies, and it is not clear if those authors who are using the term are using a methodology unique from other developing methods. Both evidence maps and scoping reviews set out to map the literature. A scoping review recently was described as "a form of knowledge synthesis that addresses an exploratory research question aimed at mapping key concepts, types of evidence, and gaps in research related to a defined area or field by systematically searching, selecting, and synthesizing existing knowledge" [3]. They recommend a process described by Arksey and colleagues and enhanced by Levac and colleagues; these steps were also referenced in other publications comparing methods of evidence synthesis as the standard for scoping reviews [14-16]. Thus, there is some consensus surrounding the scoping review method and its components. A 2013 publication attempting to distinguish between the two methodologies concluded that scoping reviews include "a descriptive narrative summary of the results" whereas evidence maps identify evidence gaps, and both use a tabular format to depict a summary of literature characteristics [14]. Furthermore, multiple publications lay out differing recommendations for evidence maps, complicating this effort $[14,17,18]$. Hence, earlier attempts by Schmucker [14] and Snilstveit [15] to characterize evidence map methods and products relied on small numbers of evidence map publications in determining their results and reached conflicting conclusions. Schmucker and colleagues' review included seven evidence maps [14]; Snilstveit discussed three examples while primarily focusing on distinguishing these from what they termed an evidence gap map [15]. Since then, more evidence maps have been published, increasing the ability to determine what constitutes an "evidence map," either in terms of methods or products. In 2014 alone, eleven evidence maps were published.

Our objectives are to identify and systematically review published evidence maps and to assess commonality and heterogeneity and to determine whether additional work is warranted to try to standardize methods and reporting. We compare and contrast the presented definitions of evidence mapping, the domains used to classify data in evidence maps, and the form of the evidence map takes.

\section{Methods}

\section{Literature search}

The librarian on our team, RS, conducted an electronic search of ten databases (PubMed, PsycINFO, Embase, CINAHL, Cochrane Database of Systematic Reviews (CDSR), Cochrane Central Register of Controlled Trials (CENTRAL), Cochrane Database of Abstracts of Reviews of Effects (DARE), Cochrane Methodology Register (CMR), SCOPUS, and Web of Science) from inception to $8 / 21 / 2015$ for publications relating to our objective by using the search terms "evidence map" OR "evidence mapping" OR "evidence maps" OR "mapping evidence" OR "evidence map" in a search of titles and abstracts. Because evidence mapping is a relatively new method in the biomedical literature synthesis repertoire, no Medical Subject Headings (MeSH) term is available. There were no language restrictions or restrictions on study design. Additional studies were identified through reference mining of identified studies and expert recommendations. 


\section{Study selection}

Two reviewers independently screened titles and abstracts for relevance and obtained full text articles of publications deemed potentially relevant by at least one reviewer. Full text articles were screened against predetermined inclusion criteria by two independent reviewers, and any disagreements were reconciled through team discussion. To be included, authors must have presented results (i.e., no protocols were included) with a process called evidence mapping or figure called an evidence map. Because of the methodological focus of this review, any patient population, intervention, comparator, outcome, and setting were included.

\section{Data abstraction}

For all included publications, the following data were abstracted: use and definition of the term "evidence map," research question or aim, search methods and years, number of citations included in the evidence map, and country of origin. The unit of analysis was also abstracted, since some maps considered all literature citations for inclusion, whereas others included systematic reviews only or aggregated all publications originating from the same study into one unit. For publications presenting maps, the domains used to classify studies in the map were also abstracted (e.g., interventions, outcomes, and literature size). Data were abstracted by one reviewer using a standardized form and verified by the second reviewer. The form was piloted and refined by both reviewers prior to abstraction. We applied no quality assessment criteria since we are unaware of any that exist for evidence map methods.

\section{Data synthesis}

Data were narratively synthesized in three sections, discussing key characteristics of definitions presented, domains used to classify literature in the mapping process (e.g., interventions), and what form an evidence map or evidence mapping methodology takes. Within this latter section, publications were grouped by whether they (1) presented a figure or table explicitly called an "evidence map" or called the results evidence mapping in the publication itself, (2) referred to an online database as the evidence map, or (3) said they used a mapping methodology but did not present a figure or table. No statistical analysis was planned or executed, given the focus on reporting of methods rather than a specific outcome and the heterogeneous nature of the included health topics. We created tables to summarize data on included articles to support the narrative synthesis.

\section{Results}

The total search results identified 145 titles through $8 / 21 / 2015$. Reference mining and expert recommendations yielded one title each for a total of 147 titles for screening. Of these titles, we included 53 potentially relevant publications after title and abstract screening. Fourteen of these publications were rejected after full text review. Four of the excluded publications identified themselves as another type of synthesis (i.e., scoping review, realist synthesis, or systematic review) in their titles [19-22]. Three excluded publications presented discussions of evidence mapping and have been incorporated into discussion where relevant $[14,15,23]$. Two publications used the term "evidence map" outside the evidence synthesis methodology context (e.g., in the context of reporting the results of a hazard assessment) [24, 25]. Another two publications used evidence from an evidence map that was created in a separate project [26, 27], one full text publication was not available [28], one publication was a duplicate citation with another previously screened citation [29], and the final study excluded explicitly stated that they used a standard systematic review protocol developed according to systematic review guidelines [30]. Having met inclusion criteria, thirty-nine publications were included at the full text review. Of these, 34 publications presented evidence maps explicitly and five publications used a mapping methodology without presenting a map [18, 31-34] (see Fig. 1 for literature flow and Additional files 1 and 2 for PRISMA checklist and flow). The publications with explicit maps included those that presented the map in the publication $(N=26)$ [35-60], and those that discussed a map only available online $(N=8)$ [16, 17, 61-66].

Included publications came from the USA $(N=19)$, Australia $(N=10)$, the UK $(N=7)$, Canada $(N=2)$, and Japan $(N=1)$. Most publications are very recent, with no publications before 2003 (see Fig. 2). Since the last systematic review of evidence maps, conducted by Schmucker and colleagues during 2013, an additional 24 evidence maps have been published, doubling the literature quantity. More details on data extracted from included publications can be found in Table 1 .

Although a variety of topics are represented in the 39 included evidence map publications, four broad topical areas account for nearly three quarters of the publications: mental health and learning disability related topics account for 11 of the publications (28\%), complimentary alternative medicine and nutrition-related topics account for seven publications each (18\% each), and traumatic brain injury and spinal cord injury account for four publications (10\%). Within the mental health group, four of the 11 publications come from the headspace research group, described in more detail below. Six of the seven complementary and alternative medicine publications come from the Veterans Affairs Evidence Synthesis Program, of which the authors of this review are a part. Three of the seven nutrition-related publications come 


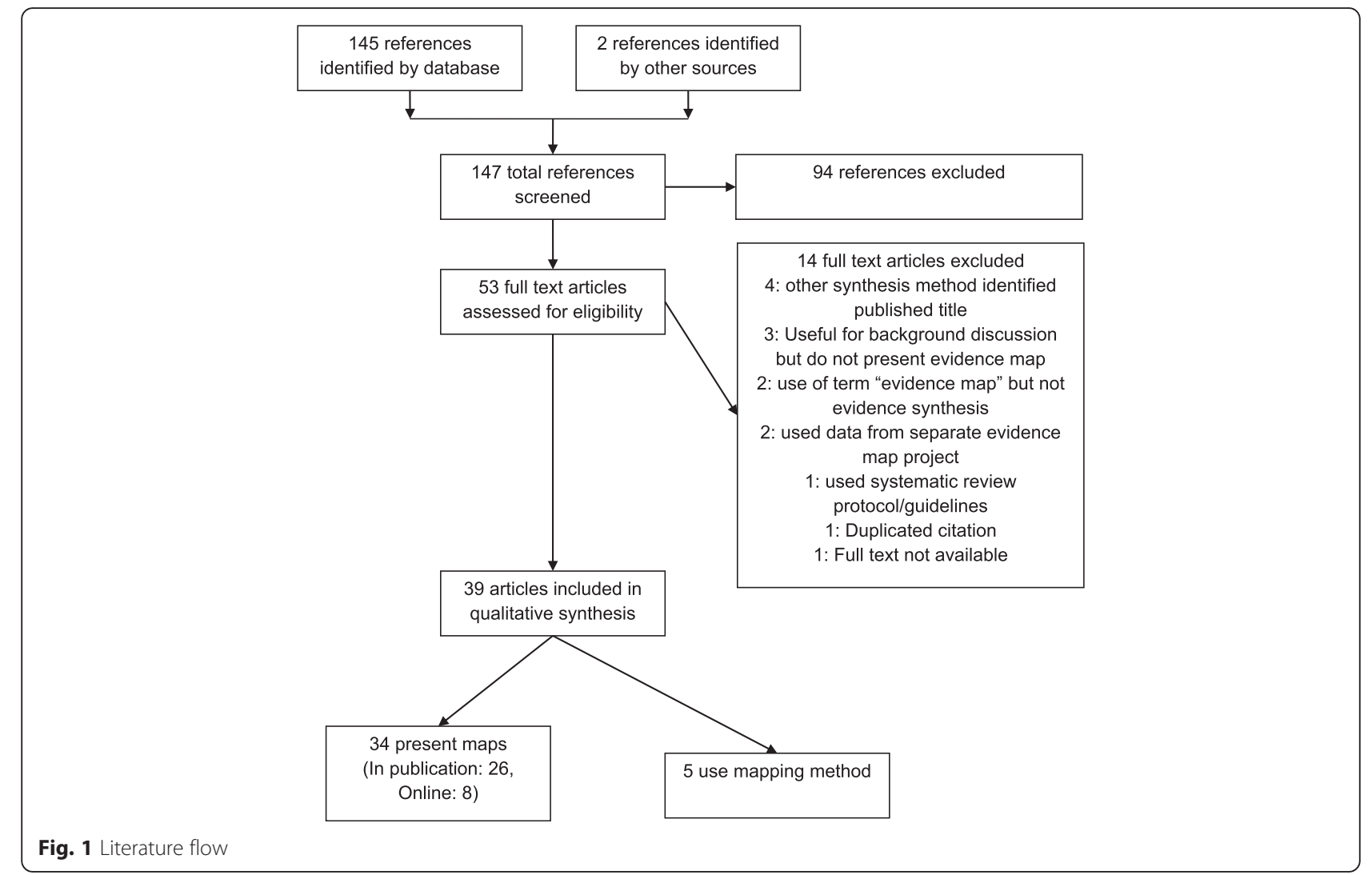

from a research group based at Tufts University, and all four of the traumatic brain injury/spinal cord injury publications are a part of the Global Evidence Mapping (GEM) project. Taken together, these four research groups account for $44 \%$ of the published evidence maps included in this review (17/39).

\section{Definition of evidence map}

Of the 39 included studies, eight were associated with two evidence mapping projects: GEM [16, 62, 64, 65]

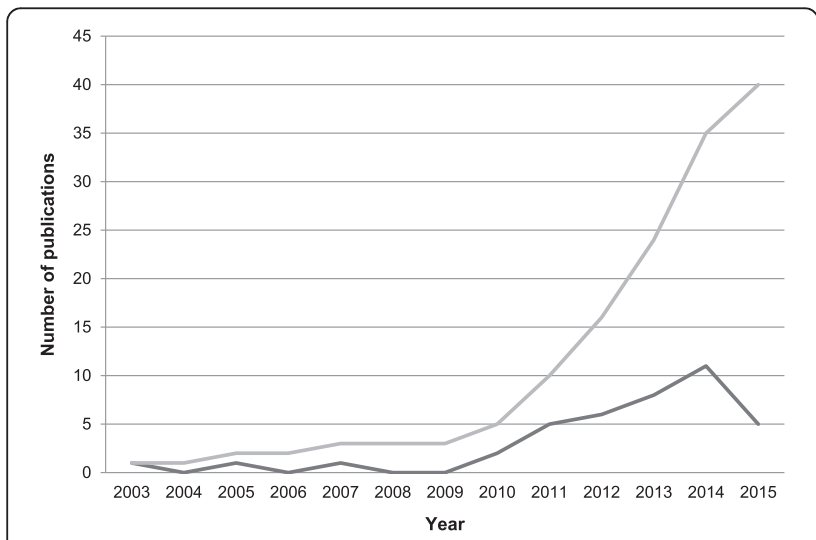

Fig. 2 Number of publications per year. The dark gray line denotes the number of publications in any given year, and the light gray line denotes the cumulative number of publications over time and headspace $[17,61,63,66]$; these publications were grouped by project in the following discussion since publications from the same project employ the same definition. In two instances, there were two publications from a single mapping project, and these were also grouped, resulting in two evidence maps from these four publications [41, 48, 49, 58]. One publication provided neither definition nor citation [32]. Most studies did not explicitly outline a definition of "evidence map," and often the research aims were used to capture an implicit definition (see Table 1 for research questions or aims for all included studies).

Thus, of the 31 evidence maps with elements of a definition, the most commonly stated component of the definition was a review of evidence to identify gaps or future research needs $(67 \%, 21 / 31)$. Another common component was that the process engage the audience and/or produce user-friendly products (58 \%, 18/31). In emphasizing the user-friendly aspect, one definition stated that evidence maps should "provide access to user-friendly summaries of the included studies" [15], while another described evidence maps as "mak[ing] these vast bodies of literature accessible, digestible, and useable" [44]. Many definitions also qualified evidence maps as capturing a broad field $(55 \%, 17 / 31)$. Two components were less often explicitly stated in the definition, having a systematic process and visual depiction 
Table 1 Table of included studies

\begin{tabular}{|c|c|c|c|c|c|}
\hline Author, year & Research question or aim & Unit of analysis & Search methods, years & $\begin{array}{l}\text { Country of } \\
\text { origin }^{\mathrm{a}}\end{array}$ & Citations for definition \\
\hline \multicolumn{6}{|c|}{ Explicit, published $(n=26)$} \\
\hline Althuis, 2013 [35] & $\begin{array}{l}\text { We intend to identify and summarize the } \\
\text { study designs, populations, and outcome } \\
\text { measures involved in sugar-sweetened } \\
\text { beverage research, providing a foundation } \\
\text { for ( } 1 \text { ) a better understanding of the } \\
\text { existing mix of studies, (2) identifying } \\
\text { research gaps informing future studies on } \\
\text { SSB, and (3) focused research synthesis } \\
\text { questions appropriate for systematic } \\
\text { review and meta-analyses. }\end{array}$ & $\begin{array}{l}\text { Original study (intervention or cohort } \\
\text { studies, } n=59 \text { ) }\end{array}$ & $\begin{array}{l}\text { Followed PRISMA guidelines, } \\
\text { multiple databases with standard } \\
\text { search terms, reference mined; } \\
\text { 1966-2012 }\end{array}$ & USA & $\begin{array}{l}\text { Bragge 2011, Levac 2010, Arksey } \\
\text { 2005, Katz 2003, Gough } 2012\end{array}$ \\
\hline Antsee, 2011 [40] & $\begin{array}{l}\text { To identify gaps among the many } \\
\text { contemporary studies on HIV prevention } \\
\text { from countries with possible relation to } \\
\text { HIV in the UK. }\end{array}$ & $\begin{array}{l}\text { Publications ( } n=716 \text { systematic } \\
\text { reviews, RCTs, other primary research } \\
\text { articles) }\end{array}$ & $\begin{array}{l}\text { Standard search in multiple } \\
\text { databases; 2006-2009 }\end{array}$ & UK & Shepherd 2007, GEM \\
\hline Bailey, 2014 [44] & $\begin{array}{l}\text { To investigate and quantify the nature } \\
\text { and distribution of existing high-quality } \\
\text { research on the prevention and treatment } \\
\text { of eating disorders in young people using } \\
\text { evidence mapping methodology. }\end{array}$ & $\begin{array}{l}\text { Trials }(n=197), \text { systematic reviews } \\
(n=22) \text {, follow-up studies }(n=10)\end{array}$ & $\begin{array}{l}\text { Standard search in multiple } \\
\text { databases; 1980-2012 }\end{array}$ & Australia & $\begin{array}{l}\text { Callahan 2012, Liu 2010, De } \\
\text { Silva } 2013\end{array}$ \\
\hline Berger, 2014 [45] & $\begin{array}{l}\text { Applying evidence mapping techniques to } \\
\text { describe the quantity, design, and } \\
\text { characteristics of the research on the broad } \\
\text { nutrition topic of sugars and health to } \\
\text { highlight both what is known and where } \\
\text { the gaps exist. }\end{array}$ & Studies $(n=213)$ & $\begin{array}{l}\text { Standard search in Medline; } \\
\text { 1946-May } 2013\end{array}$ & USA & none \\
\hline Bonell, 2013 [46] & $\begin{array}{l}\text { The purpose of the map of evidence and } \\
\text { theory and stakeholder consultations was } \\
\text { to identify references that are potentially } \\
\text { relevant to our review questions, to assess } \\
\text { the nature of the references, and to refine } \\
\text { our review questions for stage } 2 \text {. The } \\
\text { research questions for this initial mapping } \\
\text { stage focused on all aspects of schools' } \\
\text { social and physical environment. }\end{array}$ & References $(n=1,144)$ & $\begin{array}{l}\text { Standard searches in multiple } \\
\text { databases; through September } \\
2010\end{array}$ & UK & none \\
\hline Brennan, 2014 [43] & $\begin{array}{l}\text { To evaluate the growing literature on } \\
\text { policy and environmental strategies to } \\
\text { prevent childhood obesity. }\end{array}$ & Studies $(n=600)$ & $\begin{array}{l}\text { Standard search in multiple } \\
\text { databases; 2000-2009 }\end{array}$ & USA & Hetrick 2010 \\
\hline Chung, 2011 [39] & $\begin{array}{l}\text { The objectives of this technical brief are to } \\
\text { describe the current state of use of stress- } \\
\text { loading MRI technologies, to enumerate } \\
\text { their potential benefits and harms for the } \\
\text { diagnosis and management of patients with } \\
\text { musculoskeletal disorders for whom this } \\
\text { diagnostic test may be considered, and to }\end{array}$ & Studies $(n=57)$ & $\begin{array}{l}\text { Standard search in MEDLINE; } \\
1975-2010\end{array}$ & USA & none \\
\hline
\end{tabular}

Publications ( $n=716$ systematic reviews, RCTs, other primary research

Trials $(n=197)$, systematic reviews

To investigate and quantify the nature

The purpose of the map of evidence and review questions for stage 2 . The research questions for this initial mapping policy and environmental strategies to ollowed PRISMA guidelines, ultiple databases with standard terms, reference mined

Standard search in multiple

Standard search in multiple databases; 1980-2012

tandard search in Medline; 1946-May 2013

Standard searches in multiple atabases; through September

Standard search in multip
databases; 2000-2009

Standard search in MEDLINE; 975-2010 
Table 1 Table of included studies (Continued)

describe the evidence available to date that supports these applications.

Coast, 2012 [47] This study systematically maps, assesses, and aggregates research relating to postnatal depression and poverty in low and lower middle income countries.

Coeytaux, 2014 To evaluate the existing evidence on yoga $[48,49] \quad$ for common clinical conditions in Veterans

DeFrank, 2014 [42] "To understand the extent of evidence on psychological harms, we developed an evidence map that quantifies the distribution of evidence on psychological harms for five adult screening services. We also note gaps in the literature and make recommendations for future research... In characterizing the studies, we gathered information about the study designs, types of measures, and types of outcomes assessed. To focus our study's scope, we did not assess additional quality indicators of the studies or report their results."

El-Behadli, 2015 The purpose of this article is to present a map of the extent and distribution of scientific evidence regarding translations of the 9 American Academy of Pediatricsrecommended developmental screening instruments into languages other than English.

Greer, 2012 [38] The purpose: "to describe the wheeled mobility service delivery process for patients with complex rehabilitation needs, survey the available literature on service delivery, and identify issues and areas for future research."

Hempel, 2014 [51] An evidence map that provides a visual overview of the distribution of evidence (both what is known and where there is little or no evidence base) for mindfulness and a set of executive summaries that would help stakeholders interpret the state of the evidence to inform policy and clinical to inform policy and clinical decision making.

Hempel, 2014 [41, The project deliverables are an evidence map that provides a visual overview of the distribution of evidence (both what is known distribution of evidence (both what is known and where there is litle or no evidence base) or acupuncture and a set of executive summaries that would help stakeholders interpret the state of evidence to inform policy and clinical decision making.
Standard search in multiple

UK

databases; through August 2010

Standard search in multiple databases; through July 2014

Standard search in multiple databases; 2002-2012 databases; 2005-2013 
Table 1 Table of included studies (Continued)

\begin{tabular}{|c|c|c|c|c|c|}
\hline Hempel, 2014 [52] & $\begin{array}{l}\text { An evidence map that provides a visual } \\
\text { overview of the distribution of evidence } \\
\text { (both what is known and where there is } \\
\text { little or no evidence base) for Tai Chi and } \\
\text { a set of executive summaries that would } \\
\text { help stakeholders interpret the state of } \\
\text { the evidence to inform policy and clinical } \\
\text { decision-making. }\end{array}$ & Systematic reviews $(n=107)$ & $\begin{array}{l}\text { Standard search in multiple } \\
\text { databases and input from } \\
\text { experts; through February } \\
2014\end{array}$ & USA & none \\
\hline Hitch, 2012 [53] & $\begin{array}{l}\text { The purpose of this scoping and mapping } \\
\text { project is to assess evidence for the use of } \\
\text { focused psychological strategies to enable } \\
\text { people with mental health problems to } \\
\text { participate in meaningful occupations. In } \\
\text { particular, it aims to summarize and thus } \\
\text { increases accessibility to the evidence which } \\
\text { practitioners could use to support their } \\
\text { use of focused psychological strategies to } \\
\text { maximize the functional performance and } \\
\text { quality of life enjoyed by their clients. }\end{array}$ & Studies $(n=81)$ & $\begin{array}{l}\text { Standard search in multiple } \\
\text { databases; since } 2000\end{array}$ & Australia & $\begin{array}{l}\text { Arksey 2005, Bates 2007, Katz } \\
2003\end{array}$ \\
\hline Jaramillo, 2013 [37] & $\begin{array}{l}\text { To identify high-priority research questions } \\
\text { for osteoarthritis systematic reviews with } \\
\text { consideration of health equity and the } \\
\text { social determinants of health. }\end{array}$ & Systematic reviews $(n=34)$ & $\begin{array}{l}\text { Preliminary search for a } \\
\text { framework on multiple } \\
\text { databases (no dates } \\
\text { reported); multiple } \\
\text { databases for systematic } \\
\text { reviews (no dates reported) }\end{array}$ & Canada & Bragge 2011 \\
\hline Kadiyala, 2014 [54] & $\begin{array}{l}\text { This paper comprehensively maps existing } \\
\text { evidence along agriculture-nutrition } \\
\text { pathways in India and assesses both the } \\
\text { quality and coverage of the existing literature. }\end{array}$ & Articles $(n=78)$ & $\begin{array}{l}\text { Standard search in multiple } \\
\text { databases, gray literature } \\
\text { search; through June } 2013\end{array}$ & UK & none \\
\hline Nihashi, 2013 [36] & $\begin{array}{l}\text { We constructed an evidence map of clinical } \\
\text { evidence on the use of PET in glioma and } \\
\text { identified research gaps. }\end{array}$ & Studies $(n=129)$ & $\begin{array}{l}\text { Standard search in multiple } \\
\text { databases; through } 2011\end{array}$ & Japan & Arksey 2005, Hetrick 2010 \\
\hline $\begin{array}{l}\text { Northway, } 2005 \\
{[55]}\end{array}$ & $\begin{array}{l}\text { To collate the evidence for good practice } \\
\text { within the context of a wider project into } \\
\text { the abuse of people with learning } \\
\text { disabilities...it has highlighted common } \\
\text { themes, examples of good practice, and } \\
\text { the extent and nature of research that can } \\
\text { inform adult protection. }\end{array}$ & Not reported & $\begin{array}{l}\text { Standard search in multiple } \\
\text { databases; no date restricted }\end{array}$ & UK & none \\
\hline Sawicki, 2015 [56] & $\begin{array}{l}\text { To use evidence mapping to summarize } \\
\text { published data on dietary fibers and the } \\
\text { human gut microbiome. }\end{array}$ & Publications ( $n=153$ ) & $\begin{array}{l}\text { Standard search in multiple } \\
\text { databases; no dates reported }\end{array}$ & USA & none \\
\hline Singh, 2012 [57] & $\begin{array}{l}\text { The purpose of this study was to develop } \\
\text { a broad synopsis of the available literature } \\
\text { through an evidence map of systematic } \\
\text { reviews about interventions in adults with }\end{array}$ & Systematic reviews $(n=14)$ & $\begin{array}{l}\text { Standard search in multiple } \\
\text { databases and gray literature; } \\
\text { January } 2012\end{array}$ & Canada & Arksey 2005, Hetrick 2010 \\
\hline
\end{tabular}


Table 1 Table of included studies (Continued)

\begin{tabular}{|c|c|c|c|c|c|}
\hline Vallarino, 2015 [59] & $\begin{array}{l}\text { Identify the extent, distribution, and } \\
\text { methodological quality of evidence (on the } \\
\text { use of psychological interventions for } \\
\text { early-stage bipolar disorder in patients aged } \\
15-25 \text { years). }\end{array}$ & Studies $(n=29)$ & $\begin{array}{l}\text { Search in multiple databases } \\
\text { and additional sources; no } \\
\text { dates reported }\end{array}$ & UK & Hetrick 2010 \\
\hline Wang, 2015 [60] & $\begin{array}{l}\text { To describe the quantity, design, and } \\
\text { characteristics of the published studies of } \\
\text { low calorie sweeteners and selected health } \\
\text { outcomes using evidence mapping. }\end{array}$ & Studies $(n=222)$ & $\begin{array}{l}\text { Standard search on Medline; } \\
\text { through July } 2014\end{array}$ & USA & none \\
\hline \multicolumn{6}{|l|}{ Explicit, online $(n=8)$} \\
\hline GEM $[16,62,64,65]$ & $\begin{array}{l}\text { To create evidence maps providing an } \\
\text { overview of existing research in traumatic } \\
\text { brain injury (TBI) and spinal cord injury (SCI) }\end{array}$ & Publications ( $n=1644$ ) & $\begin{array}{l}\text { Standard search in multiple } \\
\text { databases; no time restriction }\end{array}$ & Australia & Bragge 2011 \\
\hline $\begin{array}{l}\text { Headspace }[17,61, \\
63,66]\end{array}$ & $\begin{array}{l}\text { In order to comprehensively and } \\
\text { systematically assemble and appraise } \\
\text { evidence for a range of treatments across } \\
\text { numerous mental health disorders (for } \\
\text { young people aged } 12-25 \text { years), a } \\
\text { mapping methodology was selected. }\end{array}$ & $\begin{array}{l}\text { See below for description } \\
\text { from individual publications }\end{array}$ & $\begin{array}{l}\text { See below for description } \\
\text { from individual publications }\end{array}$ & $\begin{array}{l}\text { See below for } \\
\text { description } \\
\text { from individual } \\
\text { publications }\end{array}$ & $\begin{array}{l}\text { Arksey 2005, Bragge 2011, } \\
\text { Hetrick 2010, Katz 2003, Curran } \\
2007\end{array}$ \\
\hline $\begin{array}{l}\text { Callahan, } 2012 \\
\text { [63] headspace }\end{array}$ & $\begin{array}{l}\text { This paper presents the results of an evidence } \\
\text { map we conducted on depression in young } \\
\text { people. The extent, range, and nature of } \\
\text { high-quality clinical research interventions } \\
\text { for depression in young people are } \\
\text { summarized. }\end{array}$ & $\begin{array}{l}\text { Publications ( } n=204,162 \\
\text { trials, } 41 \text { SR/MA) }\end{array}$ & $\begin{array}{l}\text { Standard search in multiple } \\
\text { databases; 1980-2009 }\end{array}$ & Australia & Aggregated above \\
\hline $\begin{array}{l}\text { De Silva, } 2013 \\
\text { [61] headspace }\end{array}$ & $\begin{array}{l}\text { To investigate the extent and nature of } \\
\text { research on interventions to prevent and } \\
\text { treat suicide and self-harm in young people } \\
\text { using evidence mapping. }\end{array}$ & Reviews $(n=6)$, Studies $(n=38)$ & $\begin{array}{l}\text { Standard search in multiple } \\
\text { databases; 1980-2011 }\end{array}$ & Australia & Aggregated above \\
\hline $\begin{array}{l}\text { Liu, } 2010 \\
\text { [66] headspace }\end{array}$ & $\begin{array}{l}\text { Presents an overview of the extent, range } \\
\text { and nature of high-quality clinical research } \\
\text { interventions for early psychosis by } \\
\text { summarizing the empirical evidence from } \\
\text { RCTs, CCTs, and SRs and/or MAs. }\end{array}$ & $\begin{array}{l}\text { Publications ( } n=66,58 \\
\text { controlled trials, } 8 \text { systematic } \\
\text { reviews) }\end{array}$ & $\begin{array}{l}\text { Standard search in multiple } \\
\text { databases; no dates reported }\end{array}$ & Australia & Aggregated above \\
\hline \multicolumn{6}{|l|}{ Methodology $(n=5)$} \\
\hline $\begin{array}{l}\text { Chapman, } 2013 \\
\text { [31] }\end{array}$ & $\begin{array}{l}\text { To identify gaps and priorities in the maternal } \\
\text { health research, generate a list of maternal } \\
\text { health research questions... and adapt } \\
\text { questions... to create research questions } \\
\text { for use in a future prioritization exercise } \\
\text { with experts and other stakeholders. }\end{array}$ & Systematic reviews $(n=178)$ & $\begin{array}{l}\text { Searched the Cochrane } \\
\text { Database of Systematic } \\
\text { Reviews; 2006-2011 }\end{array}$ & USA & $\begin{array}{l}\text { Li et al. 2012, Nasser et al. } \\
\text { 2007, de Vet et al. 2001, Clarke } \\
\text { et al. } 2007\end{array}$ \\
\hline Curran, 2007 [33] & $\begin{array}{l}\text { What empirical evidence is available on the } \\
\text { relationships between mental health problems } \\
\text { and social exclusion? What is the nature of } \\
\text { this evidence? Is it qualitative or quantitative? } \\
\text { Which mental health and social exclusion }\end{array}$ & $\begin{array}{l}\text { Publications ( } n=72 \text { includes } \\
\text { from a random sample of } 200 \\
\text { pulled from } 16,115 \text { total search } \\
\text { hits) }\end{array}$ & $\begin{array}{l}\text { Search in multiple databases; } \\
1948-2003\end{array}$ & USA & Gough and Elbourne 2002 \\
\hline
\end{tabular}


Table 1 Table of included studies (Continued)

Wysocki, 2007 [32] To provide an overview of the key issues and evidence map related to the use of whole-body vibration therapy for the

Standard search in multiple databases; through 2011

Standard search in multiple databases, gray literature

included; through 2000/2001

counts by category, mutual
exclusivity not addressed, all

study designs and included

systematic reviews/ meta-

Studies $(n=12)$

Standard search in multiple

databases and gray literature

None
Shepherd et al. 2010

Shepherd et al. 2006, Rees et al. 2006

USA None

${ }^{\mathrm{a}}$ For publications from more than one country, the country of the corresponding author was used 
(48 \%, 15/31 and $23 \%, 7 / 31$, respectively), but all included publications used a systematic process (i.e., documented search strategy and inclusion criteria) and most incorporated a visual depiction of the data as well $(84 \%, 26 / 31)$.

Only one evidence map definition explicitly stated all five of these components (i.e., identify gaps or needs, audience engagement/user-friendly products, broad field, systematic process, and visual depiction) [49]. Three other evidence maps met all criteria when their inclusion of a visual depiction was considered a part of the definition implicitly [39, 57, 63]. Seventeen of the evidence maps included four of the five definition components, including those that used a systematic process or visual depiction without explicitly stating this $[16,35-38,40-$ 42, 44-47, 51-53, 56]. Thus, $68 \%(21 / 31)$ evidence maps with definitions included four or five of the five most common components.

Most of the 31 evidence maps did not provide any citations when referencing evidence mapping methodology $(N=15)$. Citations occurring more than twice included Arksey and colleagues [67] $(N=8)$, the GEM project [16] $(N=7)$, the headspace project [17] $(N=5)$, and Katz and colleagues [18] $(N=3)$. The publication by Arksey and colleagues provides a description of scoping review methods but was still the most cited article. The GEM and headspace projects are both large initiatives that have funded the exploration of a very broad topic, neurotrauma and mental health disorders affecting youth, respectively. The publication by Katz and colleagues, the oldest of the publications we identified, was published in 2003, at least 4 years before any of the other identified mapping publications [18]. This publication introduces the term, as well as a nine-step process: identify and convene the appropriate experts, apply expert opinion to define the region of evidence to be mapped, establish the coordinates to be used for positioning within the map, define the map boundaries in terms of pertinent coordinates, search the relevant "terrain," draw the map, study the map to identify any needed revisions and to establish priorities for detailed assessments, perform detailed assessments in priority areas, and generate reports summarizing the "lay of the land."

\section{Domains used to classify data in evidence maps}

Only publications that presented an evidence map as a figure or online database were considered relevant in determining domains, or data elements used to classify literature, since these publications were the ones with data presented for such domains. Of the 34 publications, 26 presented the maps in the publication itself, and eight were associated with an online map. As in the definition section, duplicate publications from the same evidence mapping project were collapsed together, leaving a total of 26 evidence maps with domains for this synthesis.

Thirteen evidence maps categorized their literature by the amount of literature relevant to a particular domain (literature size domain, $50 \%$, see Table 2). Other popular domains included intervention $(N=12,46 \%)$, study design $(N=10,38 \%)$, sample size $(N=10,38 \%)$, disorder/ condition $(N=9,35 \%)$, and outcomes $(N=9,35 \%)$. Some maps grouped literature in subdomains within these larger domains, such as groups of conditions and then individual conditions within those groups. The average number of domains captured in an evidence map was four, the smallest number being two (i.e., outcomes and elements of service delivery) and the largest being seven (i.e., population characteristics, intervention, outcomes, setting, study design, sample size, and disorder/condition).

\section{Form the evidence map takes once completed}

Three main versions of an evidence map were found: publications with a visual representation of data in the publication $(N=26)$; publications that referenced a database housing data virtually that can be queried $(N=8)$; and publications that employed a process or methodology leading to recommendations or synthesized result $(N=5)$.

\section{Visual representation of data}

Twenty-six publications explicitly include figure(s) or table(s) which are referred to as evidence maps. They display a range of potential map formats, some quite similar to a classic systematic review evidence table or literature flow diagram. These formats incorporate various numbers of characteristics and types of characteristics. Details of map formats can be found in Table 2. As in prior sections, two projects with two publications each are collapsed into two groups [41, 48, 49, 58], and thus, 24 evidence maps are discussed in this section.

Most of the 24 published evidence maps used some variant of a cross-tabular format for their main findings, with counts or sums of publications arrayed across various domains $(N=10,42 \%)$. Eight bubble plots (33\%), two flow charts $(8 \%)$, and two bar charts $(8 \%)$ were used as the main findings diagram in evidence mapping publications. The last two publications arrayed included studies on a conceptual framework (8\%) and mapped the evidence on the relationships described in the model. Most publications presented data in more than one table or graphic $(N=16,67 \%)$, either with subsets of data in each map (e.g., one table for condition $\mathrm{A}$ and another for condition B) or with different domains covered in the different maps (e.g., one graphic describing population demographics covered by the literature and another with outcomes cross-tabulated with interventions of 
Table 2 Evidence map presentations and domains used to classify data in the evidence maps

\begin{tabular}{|c|c|c|c|c|c|c|c|c|c|c|c|c|c|c|}
\hline \multirow[t]{2}{*}{ Author, year } & \multirow{2}{*}{$\begin{array}{l}\text { Evidence map } \\
\text { presentations } \\
\text { Title: description } \\
\text { of map(s); all } \\
\text { identified studies } \\
\text { represented }\end{array}$} & \multicolumn{6}{|l|}{ Classic PICOTS } & \multirow{2}{*}{$\begin{array}{l}\text { Study } \\
\text { design }\end{array}$} & \multirow{2}{*}{$\begin{array}{l}\text { Sample } \\
\text { size (N) }\end{array}$} & \multirow{2}{*}{$\begin{array}{l}\text { Disorder/ } \\
\text { condition }\end{array}$} & \multicolumn{3}{|c|}{ Systematic review domains } & \multirow[t]{2}{*}{ Other, specify } \\
\hline & & $\begin{array}{l}\text { Population } \\
\text { characteristics }\end{array}$ & Intervention & Comparators & Outcomes & Timing & Setting & & & & $\begin{array}{l}\text { Literature } \\
\text { size }\end{array}$ & $\begin{array}{l}\text { Estimated } \\
\text { effect/ } \\
\text { association }\end{array}$ & $\begin{array}{l}\text { Confidence } \\
\text { in estimate }\end{array}$ & \\
\hline \multicolumn{15}{|c|}{ Explicit, published $(n=26)$} \\
\hline $\begin{array}{l}\text { Althuis, } 2013 \\
\text { [35] }\end{array}$ & $\begin{array}{l}\text { "Evidence map of } \\
\text { publications of } \\
\text { sugar-sweetened } \\
\text { beverages by } \\
\text { outcome and } \\
\text { study type"(F2): } \\
\text { flow diagram; yes, } \\
\text { "Evidence map of } \\
\text { published cohort } \\
\text { and intervention } \\
\text { studies of sugar- } \\
\text { sweetened } \\
\text { beverages by } \\
\text { outcome and } \\
\text { key study } \\
\text { features" (F3): flow } \\
\text { diagram } \\
\text { and cross-tabular } \\
\text { table hybrid; yes }\end{array}$ & $x$ & & & $x$ & $x$ & $x$ & $x$ & $x$ & & & & & \\
\hline $\begin{array}{l}\text { Antsee, } 2011 \\
{[40]}\end{array}$ & $\begin{array}{l}\text { "The matrix" (F1): } \\
\text { cross-tabular table } \\
\text { with color-coded } \\
\text { subdivisions in } \\
\text { each cell; yes }\end{array}$ & $x$ & & & & & & $x$ & & & & & & $\begin{array}{l}\text { Prevention } \\
\text { area: several } \\
\text { important } \\
\text { areas within } \\
\text { HIV prevention } \\
\text { research that } \\
\text { represent } \\
\text { potential for } \\
\text { novel and } \\
\text { innovative } \\
\text { research of } \\
\text { interest (e.g., } \\
\text { education, } \\
\text { behavior, } \\
\text { service } \\
\text { delivery, } \\
\text { descriptive } \\
\text { epidemiology, } \\
\text { international } \\
\text { adaptability, } \\
\text { etc.) }\end{array}$ \\
\hline
\end{tabular}

area: several important HIV prevention research that potential for

innovative

research of

interest (e.g

behavior,

service 
Table 2 Evidence map presentations and domains used to classify data in the evidence maps (Continued)

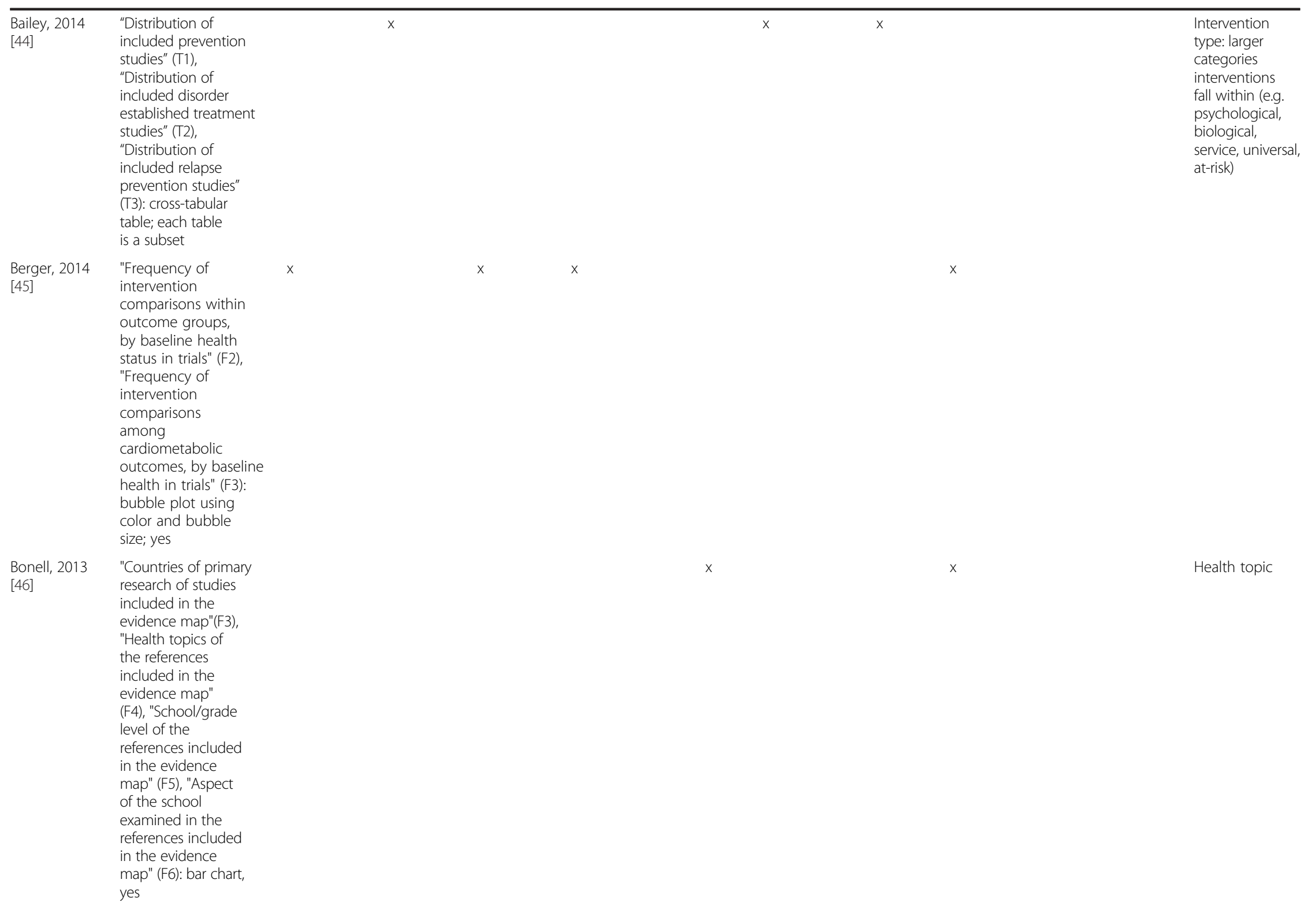


Table 2 Evidence map presentations and domains used to classify data in the evidence maps (Continued)

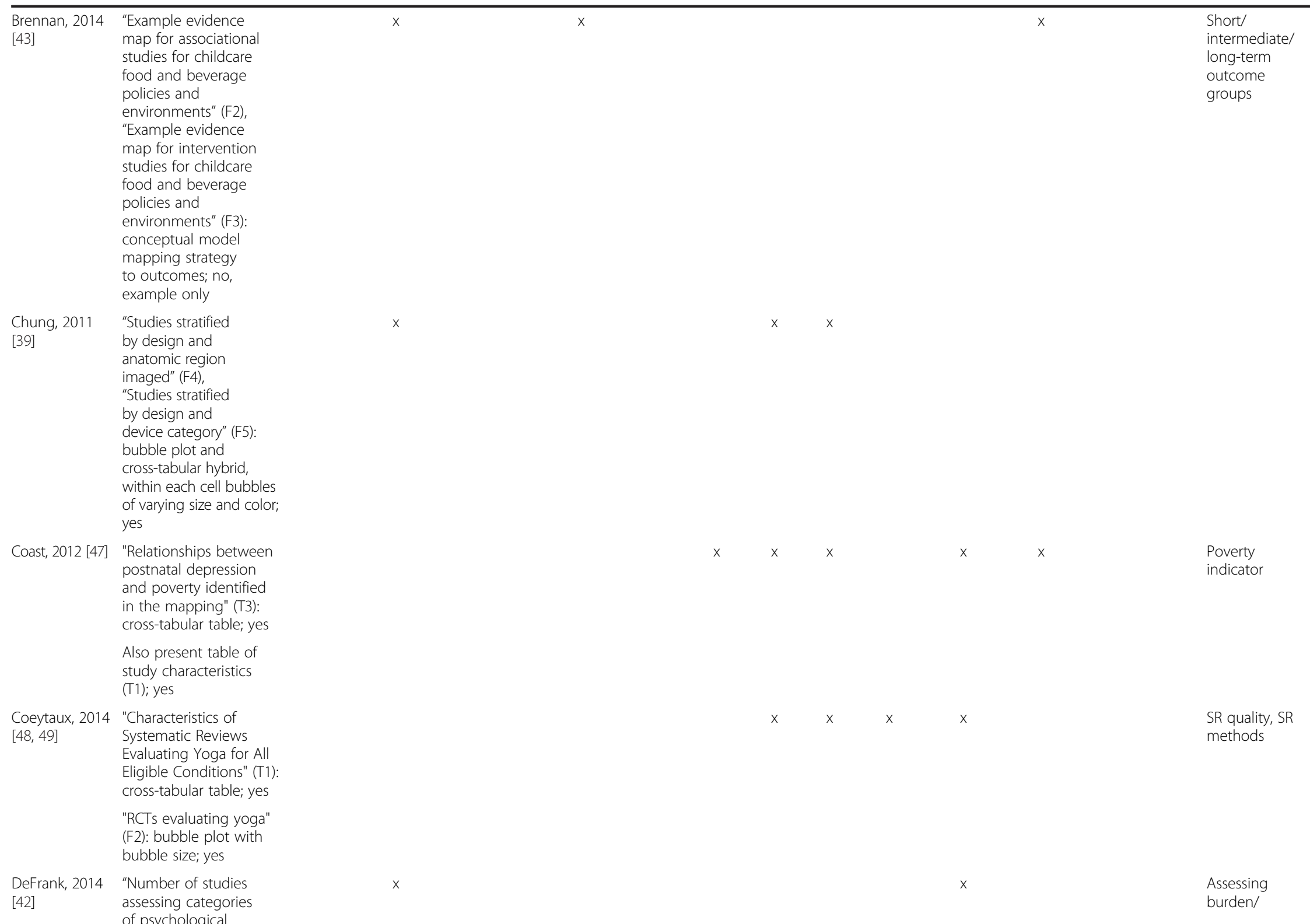


Table 2 Evidence map presentations and domains used to classify data in the evidence maps (Continued)

Greer, 2012 [38] "Summary of studies

harms and rates of

overdiagnosis" (F2):

bar graph with color-

coded subdivisions; yes

"Evidence in Peer-

El-Behadli, Reviewed Publications

2015 [50] of Translation Methods"

(T2), "Evidence in Peer-

Reviewed Journals

Regarding

Restandardization of

Translations" (T3):

cross-tabular table; yes

on wheeled mobility

service delivery" (T2):

Language,

screener

translation

methods

factors

individuals

when

considering

wheeled

mobility

options,

children's

caregivers' and

parents'

opinions

about the

wheeled

mobility used

by their child,

user

satisfaction

Hempel, 2014 "Evidence map of

$[41,58] \quad$ acupuncture for

pain" (F3), "Evidence

map of acupuncture

for wellness" (F4)

"Evidence map of

acupuncture for

mental health" (F5):

bubble plots with

color and bubble

size as dimensions 
Table 2 Evidence map presentations and domains used to classify data in the evidence maps (Continued)

Hempel, 2014 "Evidence map of tai

[52] chi" (F2): bubble plot: yes

Hitch, 2012 "Available evidence by diagnosis and focused psychological therapy" (T2), "Available evidence by diagnosis and level of evidence"

(T3), "Quality of

evidence by

intervention" (T4):

yes

Jaramillo, 2013 "Map of Evidence for

Osteoarthritis Template"

(F3): cross-tabular table;

no Online appendix

version has research

questions all mapped

to grid 
Table 2 Evidence map presentations and domains used to classify data in the evidence maps (Continued)

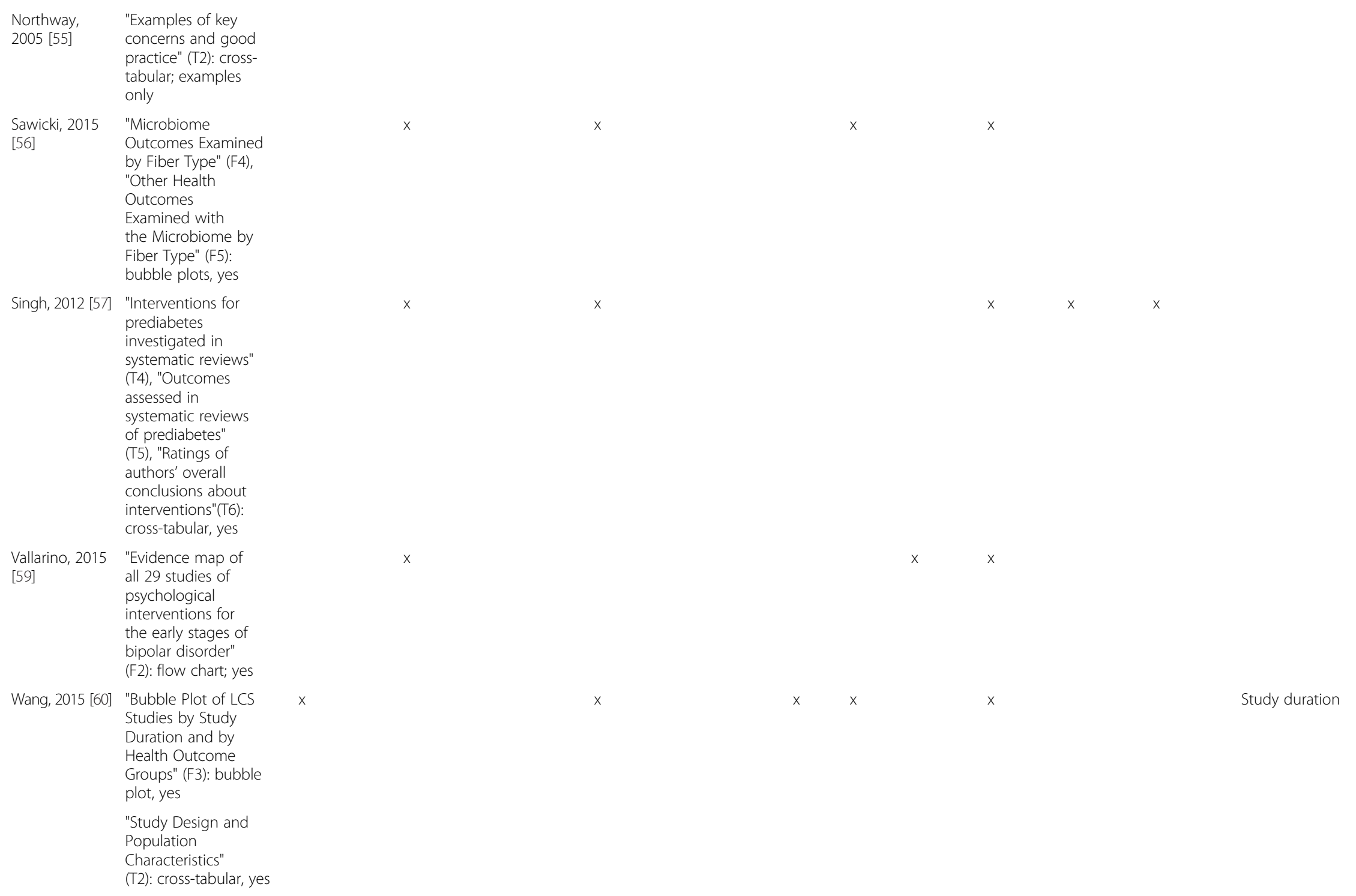

using color and stacked discs of varying size yes

concerns and good

practice" (12): cross-

Sawicki, $2015 \quad$ "M

Outcomes Examined

"Other Health

Examined with

"Interventions for

(T4), "Outcomes

assessed in

Vallarino, 2015 "Evidence map of

all 29 studies of

psychological

the early stages of

bipolar disorder

"Study Design and

Pharacteristics"

(T2): cross-tabular, yes 
Table 2 Evidence map presentations and domains used to classify data in the evidence maps (Continued)

Headspace

$[17,61,63,66]$

Callahan, 2012 "Distribution of

[63] included universal

preventive studies"

(F2), "Distribution of

included indicated

and selective

preventive studies"

(F3), "Distribution of

included studies to

treat a diagnosed

depressive disorder"

(F4): Flow diagram;

each diagram is

subset

De Silva, 2013 "The distribution of

[61] included trials in

categories during

second-stage

screening" (F2): flow

diagram; yes

Liu, 2010 [66] "Distribution of

included... studies"

(F2): flow diagram; yes 
included studies). Figure 3 presents a figure simulating a bubble plot style evidence map as an example of one of the more commonly used formats.

\section{Map as online database}

Eight publications discuss evidence maps in the context of online searchable databases. Four publications discuss GEM $[16,62,64,65]$ and four publications discuss headspace $[17,61,63,66]$. Of the four publications discussing GEM, one provides the overview of the initiative and lays out the GEM mapping method [16], one discusses search strategies that the GEM group has developed [65], and the final one discusses the process of developing priority research areas for which evidence maps can be generated [62]. For this group of publications, there is one product: the searchable online GEM database.

In the case of the headspace publications, there is an overview publication that lays out the history and scope of the headspace program and their mapping methods [17], but each of the three additional publications presents data on a subsection of the overall evidence map $[61,63,66]$. While the overall program aims to improve evidence-based practice in youth mental health, the subtopics of interventions for depression, suicidal and selfharming behaviors, and psychosis are explored in depth in the latter publications, making it less clear if the overall database is the evidence map, or if the data presented within the topic-specific publications are the evidence maps. Although none of the figures are titled "evidence map," they appear similar to some of those included in the prior section.

\section{Use of evidence mapping as methodology}

Five publications used a mapping methodology without presenting an explicit map [18, 31-34]. With or without producing either of the first two conceptions of an evidence map, the third idea was presented or discussed in all included publications. The process, either discussed or executed, usually included a search of multiple databases with standard search terms, discussion of inclusion criteria, and inclusion of stakeholders in defining and/or refining the scope of the product.

\section{Discussion}

The principal conclusion of our evaluation of studies that call themselves "evidence maps" is that the implied definition, as defined by a majority of studies reporting individual components, of what constitutes an evidence map is a systematic search of a broad field to identify gaps in knowledge and/or future research needs that presents results in a user-friendly format, often a visual figure or graph, or a searchable database. However, only four of 31 studies (12\%) satisfied all five of these components. Thus, the heterogeneity in methods and stated definitions means that stakeholders cannot necessarily know what to expect if they commission an evidence map or seek to identify existing maps.

Of all literature synthesis methods, this evidence mapping definition shares many similarities with the definition or goals of a scoping review. Both seek to review broad topics, often with the stated goal of identifying research gaps and areas for future research. In evidence mapping publications, the most often cited article for

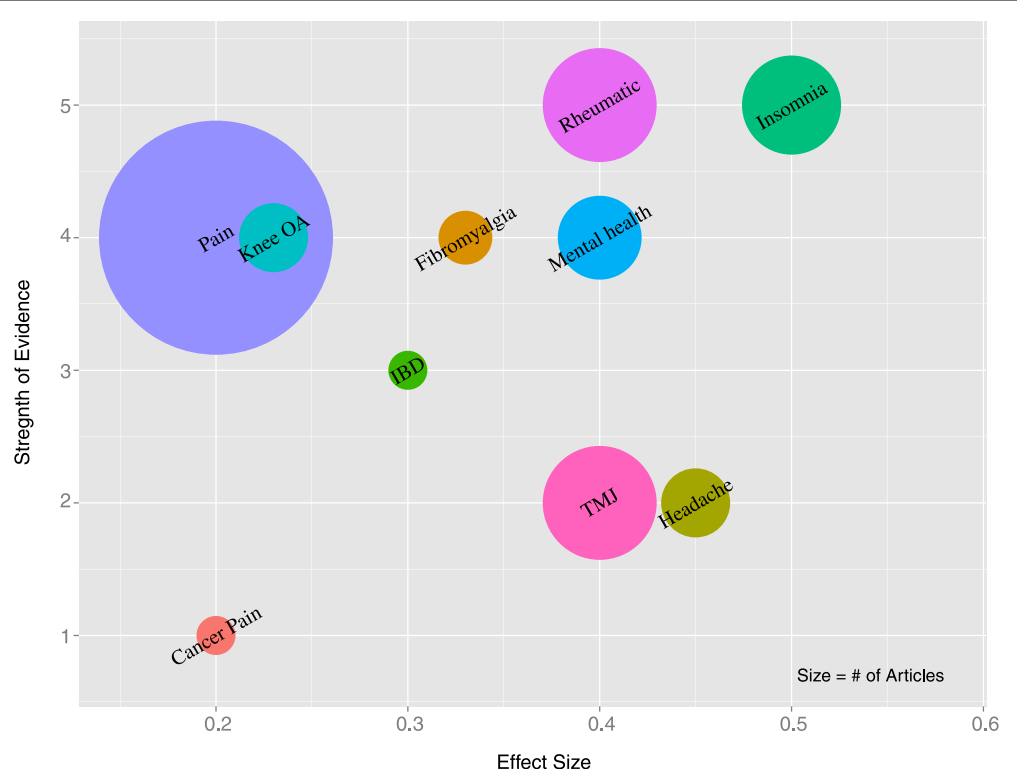

Fig. 3 Evidence map of acupuncture for pain. The bubble plot shows an estimate of the evidence base for pain-related indications judging from systematic reviews and recent large trials. The plot depicts the estimated number of RCTs (size of the bubble), the effect size ( $x$-axis), and the strength of evidence (y-axis) 
evidence mapping methods is a scoping methods publication [67]. Compared to a scoping review, using the framework suggested by Colquhoun and colleagues [3], the methods used in the evidence mapping publications are, on a whole, very similar. The main distinctions seem to be the involvement of stakeholders early in the research process, the rigor of the search strategy (e.g., all mapping publications describing systematic searches of online databases), and the production of a visual or searchable database, with the stated goal that such products are more "user-friendly" or digestible. Because neither methodology has established reporting guidelines, it is difficult to determine where one method ends and the other begins.

In terms of the "map," the most common ways of organizing the data into a visual representation were using a cross-tabular format and categorizing literature according to interventions and/or study designs present. However, the domains chosen to display and means of presentation will necessarily vary for any particular map according to the aims of the review.

\section{Limitations}

Because there is no standard search term or repository for evidence maps, we may not have been able to identify all evidence maps through our search methods. Thus, our findings may be biased to represent those maps that were readily available on the ten searched databases or were cited in other sources we found.

\section{Future research}

With growing numbers of publications using the term "evidence map," clarifying scoping and evidence mapping methods is an important topic for stakeholders so that they will know what to expect when commissioning, conducting, and interpreting results of an "evidence map." A key part of this effort will be developing reporting guidelines for these methods. This is already underway for scoping reviews [3], but given the similarities between the two methods, working on both methods in tandem may produce more clear and distinct results.

A key strength of the evidence mapping method is the use of visuals or interactive, online databases. Keeping these data up to date and available online may prove to be a challenge in rapidly growing fields, and new audiences may be exposed to these resources who are unfamiliar with how to best make use of the products. As evidence synthesis methods evolve to meet modern demands, they must also meet new challenges.

\section{Conclusions}

The principal conclusion of our evaluation is that the implied definition of what constitutes an evidence map is a systematic search of a broad field to identify gaps in knowledge and/or future research needs that presents results in a user-friendly format, often a visual figure or graph, or a searchable database. However, there is diversity in methods and stated definitions, so that, as it stands now, stakeholders cannot necessarily know what to expect if they commission an evidence map or seek to identify existing maps.

\section{Additional files}

\section{Additional file 1: PRISMA Checklist. (DOC 63 kb)}

Additional file 2: PRISMA Flow. (DOC $57 \mathrm{~kb}$ )

\section{Abbreviations}

GEM: Global Evidence Mapping.; MeSH: Medical Subject Headings; PROSPERO: International Prospective Register of Systematic Reviews.

\section{Competing interests}

The authors declare that they have no competing interests.

\section{Authors' contributions}

IML participated in the conception, design, data acquisition, and data analysis and drafted the manuscript. PGS participated in the conception, design, data analysis, and drafting of the manuscript. SH participated in the data interpretation and revising the manuscript. RS participated in data acquisition and helped to revise the manuscript. All authors read and approved the final manuscript.

\section{Acknowledgements}

We were funded by the VA Evidence Synthesis Program.

\section{Author details}

${ }^{1}$ Evidence-based Synthesis Program (ESP) Center, Veterans Affairs Greater Los Angeles Healthcare System, 11301 Wilshire Blvd, Los Angeles, CA 90073, USA. ${ }^{2}$ Department of Health Policy and Management, Fielding School of Public Health, University of California, Los Angeles, 640 Charles E Young Dr S, Los Angeles, CA, USA. ${ }^{3}$ Southern California Evidence-based Practice Center, RAND Corporation, 1776 Main St, Santa Monica, CA 90401, USA. ${ }^{4}$ Department of Medicine, David Geffen School of Medicine, University of California, Los Angeles, 10833 Le Conte Ave, Los Angeles, CA 90095, USA.

Received: 4 June 2015 Accepted: 2 February 2016

Published online: 10 February 2016

\section{References}

1. Bastian H, Glasziou P, Chalmers I. Seventy-five trials and eleven systematic reviews a day: how will we ever keep up? PLoS Med. 2010;7(9):e1000326.

2. Tricco AC, Antony J, Zarin W, Strifler L, Ghassemi M, Ivory J, et al. A scoping review of rapid review methods. BMC Med. 2015;13(1):224.

3. Colquhoun HL, Levac D, O'Brien KK, Straus S, Tricco AC, Perrier L, et al. Scoping reviews: time for clarity in definition, methods, and reporting. J Clin Epidemiol. 2014;67(12):1291-4.

4. Pawson R, Greenhalgh T, Harvey G, Walshe K. Realist review-a new method of systematic review designed for complex policy interventions. J Health Serv Res Policy. 2005;10 suppl 1:21-34.

5. Moher D, Liberati A, Tetzlaff J, Altman DG. Preferred reporting items for systematic reviews and meta-analyses: the PRISMA statement. Ann Intern Med. 2009;151(4):264-9.

6. Institute of Medicine. Finding what works in health care: Standards for Systematic Reviews. Available from: https://iom.nationalacademies.org/ Reports/2011/Finding-What-Works-in-Health-Care-Standards-for-SystematicReviews/Standards.aspx. Washington, DC2011. Accessed 9 February 2016.

7. Wong G, Greenhalgh T, Westhorp G, Buckingham J, Pawson R. RAMESES publication standards: realist syntheses. BMC Med. 2013;11(1):21.

8. Wong G, Greenhalgh T, Westhorp G, Buckingham J, Pawson R. RAMESES publication standards: meta-narrative reviews. BMC Med. 2013;11(1):20. 
9. Khangura S, Konnyu K, Cushman R, Grimshaw J, Moher D. Evidence summaries: the evolution of a rapid review approach. Syst Rev. 2012;1(1):1-9.

10. Polisena J, Garritty C, Kamel C, Stevens A, Abou-Setta AM. Rapid review programs to support health care and policy decision making: a descriptive analysis of processes and methods. Syst Rev. 2015;4(1):1-7.

11. Varker T, Forbes D, Dell L, Weston A, Merlin T, Hodson S, et al. Rapid evidence assessment: increasing the transparency of an emerging methodology. J Eval Clin Pract. 2015.

12. Ganann R, Ciliska D, Thomas H. Expediting systematic reviews: methods and implications of rapid reviews. Implement Sci. 2010;5(1):56.

13. Harker J, Kleijnen J. What is a rapid review? A methodological exploration of rapid reviews in Health Technology Assessments. Int J Evid-Based Healthc. 2012;10(4):397-410.

14. Schmucker C, Motschall E, Antes G, Meerpohl JJ. Methods of evidence mapping. A systematic review. Bundesgesundheitsblatt, Gesundheitsforschung, Gesundheitsschutz. 2013;56(10):1390-7. doi:10.1007/s00103-013-1818-y.

15. Snilstveit B, Vojtkova M, Bhavsar A, Gaarder M. Evidence gap maps-a tool for promoting evidence-informed policy and prioritizing future research. 2013.

16. Bragge P, Clavisi O, Turner T, Tavender E, Collie A, Gruen RL. The global evidence mapping initiative: scoping research in broad topic areas. BMC Med Res Methodol. 2011;11:92. doi:10.1186/1471-2288-11-92.

17. Hetrick SE, Parker AG, Callahan P, Purcell R. Evidence mapping: illustrating an emerging methodology to improve evidence-based practice in youth mental health. J Eval Clin Pract. 2010;16(6):1025-30. doi:10.1111/j.1365-2753. 2008.01112.x.

18. Katz DL, Williams AL, Girard C, Goodman J, Comerford B, Behrman A, et al. The evidence base for complementary and alternative medicine: methods of evidence mapping with application to CAM. Altern Ther Health Med. 2003;9(4):22-30

19. Costello LA, Lithander FE, Gruen RL, Williams LT. Nutrition therapy in the optimisation of health outcomes in adult patients with moderate to severe traumatic brain injury: findings from a scoping review. Injury. 2014. doi:10, 1016/j.injury.2014.06.004.

20. Brown HE, Atkin AJ, Panter J, Corder K, Wong G, Chinapaw MJ, et al. Familybased interventions to increase physical activity in children: a meta-analysis and realist synthesis protocol. BMJ Open. 2014;4(8):e005439. doi:10.1136/ bmjopen-2014-005439.

21. Boeni F, Spinatsch E, Suter K, Hersberger KE, Arnet I. Effect of drug reminder packaging on medication adherence: a systematic review revealing research gaps. Syst Rev. 2014;3:29. doi:10.1186/2046-4053-3-29.

22. Althuis MD, Weed DL, Frankenfeld CL. Evidence-based mapping of design heterogeneity prior to meta-analysis: a systematic review and evidence synthesis. Syst Rev. 2014;3:80. doi:10.1186/2046-4053-3-80.

23. John BE. Evidence-based practice in human-computer interaction and evidence maps. Proceedings of the 2005 workshop on Realising evidencebased software engineering. St. Louis, Missouri: ACM; 2005:1-5.

24. Wiedemann P, Schutz H, Spangenberg A, Krug HF. Evidence maps: communicating risk assessments in societal controversies: the case of engineered nanoparticles. Risk Anal. 2011;31(11):1770-83. doi:10.1111/j.1539-6924.2011.01725.x.

25. Chorpita BF, Daleiden EL. Mapping evidence-based treatments for children and adolescents: application of the distillation and matching model to 615 treatments from 322 randomized trials. J Consult Clin Psychol. 2009;77(3): 566-79. doi:10.1037/a0014565.

26. Bayley MT, Teasell RW, Wolfe DL, Gruen RL, Eng JJ, Ghajar J, et al. Where to build the bridge between evidence and practice?: results of an international workshop to prioritize knowledge translation activities in traumatic brain injury care. J Head Trauma Rehabil. 2014;29(4):268-76. doi:10.1097/htr.0000000000000053.

27. Scott J. What interventions can be used in high risk offspring? An evidence map of currently available therapies, and their potential for preventing disease onset or progression. Int J Neuropsychopharmacol. 2014;17:14

28. Clavisi O, Gruen R, Bragge P, Tavender E. A systematic method of identifying and prioritising research questions. Oral presentation at the 16th Cochrane Colloquium: Evidence in the era of globalisation; 2008 Oct 3-7; Freiburg, Germany [abstract]. Zeitschrift fur Evidenz, Fortbildung und Qualitat im Gesundheitswesen 2008.

29. Liu P, Parker A, Hetrick S, Purcell R. Evidence mapping for early psychotic disorders in young people. Schizophr Res. 2010;117(2-3):438-9.

30. Voigt-Radloff S, Ruf G, Vogel A, van Nes F, Hull M. Occupational therapy for elderly: evidence mapping of randomised controlled trials from 2004-2012. Z Gerontol Geriatr. 2013. doi:10.1007/s00391-013-0540-6.
31. Chapman E, Reveiz L, Chambliss A, Sangalang S, Bonfill X. Cochrane systematic reviews are useful to map research gaps for decreasing maternal mortality. J Clin Epidemiol. 2013;66(1):105-12. doi:10.1016/j.jclinepi.2012.09.005.

32. Wysocki A, Butler M, Shamliyan T, Kane RL. Whole-body vibration therapy for osteoporosis. 2011. Rockville MD.

33. Curran C, Burchardt T, Knapp M, McDaid D, Li B. Challenges in multidisciplinary systematic reviewing: a study on social exclusion and mental health policy. Social Policy Adm. 2007;41(3):289-312.

34. Frampton GK, Harris P, Cooper K, Cooper T, Cleland J, Jones J, et al. Educational interventions for preventing vascular catheter bloodstream infections in critical care: evidence map, systematic review and economic evaluation. Health Technol Assess. 2014;18(15):1-365. doi:10.3310/hta18150.

35. Althuis MD, Weed DL. Evidence mapping: methodologic foundations and application to intervention and observational research on sugar-sweetened beverages and health outcomes. Am J Clin Nutr. 2013;98(3):755-68. doi:10.3945/ajcn.113.058917

36. Nihashi T, Dahabreh IJ, Terasawa T. PET in the clinical management of glioma: evidence map. AJR Am J Roentgenol. 2013;200(6):W654-60. doi:10.2214/ajr.12.9168.

37. Jaramillo A, Welch VA, Ueffing E, Gruen RL, Bragge P, Lyddiatt A, et al. Prevention and self-management interventions are top priorities for osteoarthritis systematic reviews. J Clin Epidemiol. 2013;66(5):503-10. doi:10.1016/j.jclinepi.2012.06.017. e4.

38. Greer N, Brasure M, Wilt TJ. Wheeled mobility (wheelchair) service delivery. 2012. Rockville MD.

39. Chung M, Dahabreh IJ, Hadar N, Ratichek SJ, Gaylor JM, Trikalinos TA, et al. Emerging MRI Technologies for Imaging Musculoskeletal Disorders Under Loading Stress [Internet]. Rockville (MD): Agency for Healthcare Research and Quality (US); 2011. http://www.ncbi.nlm.nih.gov/books/NBK82287/. Accessed 9 February 2016.

40. Anstee S, Price A, Young A, Barnard K, Coates B, Fraser S, et al. Developing a matrix to identify and prioritise research recommendations in HIV prevention. BMC Public Health. 2011;11:381. doi:10.1186/1471-2458-11-381.

41. Hempel S, Taylor SL, Solloway MR, Miake-Lye IM, Beroes JM, Shanman R, et al. Evidence Map of Acupuncture [Internet]. Washington (DC): Department of Veterans Affairs; 2014 Jan. Available from: http://www.ncbi. nlm.nih.gov/books/NBK185072/. Accessed 9 February 2016.

42. DeFrank JT, Barclay C, Sheridan S, Brewer NT, Gilliam M, Moon AM, et al. The psychological harms of screening: the evidence we have versus the evidence we need. J Gen Intern Med. 2014. doi:10.1007/s11606-014-2996-5.

43. Brennan LK, Brownson RC, Orleans CT. Childhood obesity policy research and practice: evidence for policy and environmental strategies. Am J Prev Med. 2014;46(1):e1-e16. doi:10.1016/j.amepre.2013.08.022

44. Bailey AP, Parker AG, Colautti LA, Hart LM, Liu P, Hetrick SE. Mapping the evidence for the prevention and treatment of eating disorders in young people. J Eat Disord. 2014;2:5. doi:10.1186/2050-2974-2-5.

45. Berger S, Wang D, Sackey J, Brown C, Chung M. Sugars and health: Applying evidence mapping techniques to assess the evidence. FASEB Journal. 2014;28(1):Supplement 630.10.

46. Bonell C, Jamal F, Harden A, Wells H, Parry W, Fletcher A et al. Public Health Research. Systematic review of the effects of schools and school environment interventions on health: evidence mapping and synthesis. Southampton (UK): NIHR Journals Library; 2013.

47. Coast E, Leone T, Hirose A, Jones E. Poverty and postnatal depression: a systematic mapping of the evidence from low and lower middle income countries. Health Place. 2012;18(5):1188-97.

48. Coeytaux RR, McDuffie J, Goode A, Cassel S, Porter WD, Sharma P, et al. Evidence map of yoga for high-impact conditions affecting veterans. Washington (DC): Department of Veterans Affairs (US); 2014.

49. Duan-Porter W, Coeytaux RR, McDuffie J, Goode A, Sharma P, Mennella H, et al. Evidence map of yoga for depression, anxiety and post-traumatic stress disorder. J Phys Act Health. 2015. doi:10.1123/jpah.2015-0027.

50. El-Behadli AF, Neger EN, Perrin EC, Sheldrick RC. Translations of developmental screening instruments: an evidence map of available research. J Dev Behav Pediatr. 2015;36(6):471-83. doi:10.1097/dbp.0000000000000193.

51. Hempel S, Taylor SL, Marshall NJ, Miake-Lye IM, Beroes JM, Shanman R, et al. Evidence map of mindfulness. VA evidence-based synthesis program reports. Washington (DC): Department of Veterans Affairs (US); 2014.

52. Hempel S, Taylor SL, Solloway MR, Miake-Lye IM, Beroes JM, Shanman R, et al. Evidence map of Tai Chi. Washington (DC): Department of Veterans Affairs (US); 2014. 
53. Hitch D. Better access to mental health: mapping the evidence supporting participation in meaningful occupations. Advances in Mental Health. 2012;10(2):181-9.

54. Kadiyala S, Harris J, Headey D, Yosef S, Gillespie S. Agriculture and nutrition in India: mapping evidence to pathways. Ann N Y Acad Sci. 2014;1331: 43-56. doi:10.1111/nyas.12477.

55. Northway R, Davies R, Jenkins R, Mansell I. Evidencing good practice in adult protection: informing the protection of people with learning disabilities from abuse. J Adult Prot. 2005;7(2):28-36.

56. Sawicki C, Livingston K, Obin M, Roberts S, Chung M, McKeown N. Dietary fiber and the human gut microbiome: application of evidence mapping methodology. FASEB Journal. 2015;29(1):Supplement 736.27.

57. Singh K, Ansari M, Galipeau J, Garritty C, Keely E, Malcolm J, et al. An evidence map of systematic reviews to inform interventions in prediabetes. Can J Diabetes. 2012;36(5):281-91.

58. Taylor S, Hempel S, Solloway M, Miake-Lye I, Beroes J, Shekelle P. An evidence map of the effects of acupuncture. J Altern Complement Med. 2014;20(5):A91-2.

59. Vallarino M, Henry C, Etain B, Gehue LJ, Macneil C, Scott EM, et al. An evidence map of psychosocial interventions for the earliest stages of bipolar disorder. Lancet Psychiatry. 2015;2(6):548-63.

60. Wang DD, Shams-White M, Bright OJ, Chung M. Low-calorie sweeteners and health. FASEB Journal. 2015;29(1):Supplement 587.12.

61. De Silva S, Parker A, Purcell R, Callahan P, Liu P, Hetrick S. Mapping the evidence of prevention and intervention studies for suicidal and selfharming behaviors in young people. Crisis. 2013;34(4):223-32. doi:10.1027/ 0227-5910/a000190.

62. Clavisi O, Bragge P, Tavender E, Turner T, Gruen RL. Effective stakeholder participation in setting research priorities using a Global Evidence Mapping approach. J Clin Epidemiol. 2013;66(5):496-502. doi:10.1016/j. jclinepi.2012.04.002. e2.

63. Callahan P, Liu P, Purcell R, Parker AG, Hetrick SE. Evidence map of prevention and treatment interventions for depression in young people. Depress Res Treat. 2012;2012:820735. doi:10.1155/2012/820735.

64. Bragge P, Chau M, Pitt VJ, Bayley MT, Eng JJ, Teasell RW, et al. An overview of published research about the acute care and rehabilitation of traumatic brain injured and spinal cord injured patients. J Neurotrauma. 2012;29(8): 1539-47. doi:10.1089/neu.2011.2193.

65. Parkhill AF, Clavisi O, Pattuwage L, Chau M, Turner T, Bragge $P$, et al. Searches for evidence mapping: effective, shorter, cheaper. J Med Libr Assoc. 2011;99(2): 157-60. doi:10.3163/1536-5050.99.2.008.

66. Liu P, Parker AG, Hetrick SE, Callahan P, de Silva S, Purcell R. An evidence map of interventions across premorbid, ultra-high risk and first episode phases of psychosis. Schizophr Res. 2010;123(1):37-44. doi:10.1016/j.schres. 2010.05.004

67. Arksey H, O'Malley L. Scoping studies: towards a methodological framework Int J Soc Res Methodol. 2005;8(1):19-32.

\section{Submit your next manuscript to BioMed Central and we will help you at every step:}

- We accept pre-submission inquiries

- Our selector tool helps you to find the most relevant journal

- We provide round the clock customer support

- Convenient online submission

- Thorough peer review

- Inclusion in PubMed and all major indexing services

- Maximum visibility for your research

Submit your manuscript at www.biomedcentral.com/submit

) Biomed Central 